\title{
Praktik Pemberian Makan dan Perawatan Kesehatan Anak di Kelompok Bermain Al Azhar 1
}

\author{
Amalina Ratih Puspa ${ }^{1}$, Lusi Anindia Rahmawati ${ }^{2}$ \\ ${ }^{1}$ Program Studi Gizi, Fakultas Sains dan Teknologi, Universitas Al Azhar Indonesia, Jl. Sisingamangaraja \\ No.2, RT.2/RW.1, Selong, Kebayoran Baru, Kota Jakarta Selatan, DKI Jakarta 12110 \\ Penulis untuk Korespondensi/E-mail: amalina.puspa@uai.ac.id
}

\begin{abstract}
Abstrak - Kekurangan zat gizi pada saat usia balita dapat menghambat pertumbuhan dan perkembangan yang bersifat irreversible dan berdampak pada rendahnya kualitas sumberdaya manusia. Penelitian cross sectional ini bertujuan menilai praktik pemberian makan dan perawatan kesehatan anak di Kelompok Bermain Al Azhar 1. Penelitian dilakukan pada bulan Maret-November 2019 di Kelompok Bermain Al Azhar 1, Kebayoran Baru, Jakarta Selatan. Data primer diperoleh melalui wawancara menggunakan kuesioner. Pengukuran berat badan menggunakan timbangan digital, sedangkan pengukuran tinggi badan menggunakan microtoise. Subjek penelitian dipilih secara purposive sampling terdiri atas 26 ibu dan balita usia 13-59 bulan. Hasil penelitian menunjukkan bahwa hampir sebagian besar subjek memiliki status gizi yang normal berdasarkan indeks berat badan menurut umur $(\mathrm{BB} / \mathrm{U})$, tinggi badan menurut umur $(\mathrm{TB} / \mathrm{U})$, dan berat badan menurut tinggi badan (BB/TB) berturut-turut sebesar $88 \%, 92 \%$, dan 84\%. Namun demikian, masih ditemukan subjek yang tergolong memiliki status gizi kurang (4\%), gizi lebih $(8 \%)$, pendek (4\%), kurus (4\%), dan gemuk $(12 \%)$. Lebih dari separuh orangtua subjek tergolong memiliki praktik pemberian makan dan perawatan kesehatan yang baik yaitu berturut-turut sebesar $60 \%$ dan $84 \%$. Peran ibu dan anggota keluarga lain yang sehari-hari bersama balita masih perlu ditingkatkan dalam memberikan contoh praktik pemberian makan dan perawatan kesehatan yang baik pada anak.
\end{abstract}

Abstract - Nutritional deficiencies at the age of under five can inhibit irreversible growth and development and have an impact on the poor quality of human resources. This cross-sectional study aims to assess the practice of child feeding and health care in the Al Azhar 1 Play Group. The study was conducted in March-November 2019 in the Al Azhar 1 Play Group, Kebayoran Baru, South Jakarta. Primary data obtained through interviews using a questionnaire. Bodyweight measurements using digital scales, while height measurements using a microtome. The research subjects were selected by purposive sampling consisting of 26 mothers and toddlers aged 13-59 months. The results showed that most of the subjects had normal nutritional status based on body weight index according to age $(\mathrm{BB} / \mathrm{U})$, height by age (TB / U), and weight by height (BB/TB) respectively by $88 \%, 92 \%$, and $84 \%$. However, still found subjects classified as having poor nutritional status $(4 \%)$, overnutrition $(8 \%)$, short $(4 \%)$, thin $(\mathbf{4 \%})$, and fat $(\mathbf{1 2 \%})$. More than half of the parents of subjects classified as having good feeding and health care practices are $60 \%$ and $84 \%$, respectively. The role of mothers and other family members still needs to be improved in providing examples of good feeding practices and health care for children.

Keywords - Toddlers, Feeding practices, Health care, Nutritional status

\section{PENDAHULUAN}

$\mathrm{S}$ umber daya manusia (SDM) yang berkualitas dan unggul merupakan salah satu modal pembangunan suatu bangsa. Salah satu cara untuk membentuk sumber daya manusia yang berkualitas yaitu melalui pemenuhan kebutuhan dan kecukupan gizi masyarakat [1]. Kekurangan gizi pada usia dini dapat menyebabkan terhambatnya pertumbuhan dan perkembangan. Selain itu, kekurangan gizi juga dapat menyebabkan seseorang rentan terkena penyakit infeksi sebagai akibat menurunnya daya tahan tubuh dan dalam jangka panjang dapat meningkatkan risiko terkena penyakit tidak 
menular seperti obesitas, diabetes melitus, hipertensi, dan lain-lain. Hal tersebut apabila tidak ditangani serius dari berbagai pihak dapat menurunkan produktivitas SDM Indonesia dan kemudian menghambat pertumbuhan ekonomi, pembangunan nasional, dan rendahnya daya saing bangsa.

Balita merupakan kelompok yang paling rawan terdampak masalah gizi. Balita merupakan masa emas dimana tubuh memerlukan asupan zat gizi dalam jumlah besar untuk memenuhi puncak pertumbuhan dan perkembangannya. Kekurangan gizi dalam periode ini dapat menghambat pertumbuhan dan perkembangan hingga masa dewasa dan bersifat irreversible (tidak dapat diulang kembali). Oleh karena itu, status gizi balita perlu menjadi perhatian bagi setiap orangtua [2].

Salah satu faktor yang menjadi penyebab tidak langsung terjadinya masalah gizi pada balita adalah pola asuh terhadap anak. Pola pengasuhan anak berupa sikap dan perilaku ibu atau pengasuh lain dalam hal kedekatannya dengan anak, cara memberikan makan maupun pengetahuan tentang jenis makanan yang harus diberikan sesuai umur dan kebutuhan, perawatan kesehatan, dan memberi kasih sayang [3]. Praktik pemberian makan orangtua memegang peranan penting dalam membentuk kebiasaan makan balita di masa dewasa [4].

Selain pola asuh anak, masalah gizi juga dapat disebabkan oleh kondisi sosial ekonomi keluarga.Hasil penelitian menunjukkan bahwa prevalensi stunting 2,5 kali lebih tinggi terjadi di perdesaan dibandingkan perkotaan [5]. Namun, pemerintah menyebutkan bahwa stunting tidak hanya terjadi pada keluarga yang tidak mampu, melainkan masih terjadi di keluarga yang mampu. PAUD Al Azhar Indonesia terletak di perkotaan dan sebagian besar siswa/siswi PAUD Al Azhar Indonesia tergolong memiliki status sosial ekonomi menengah ke atas.

Penelitian ini bertujuan untuk menilai praktik pemberian makan dan perawatan kesehatan anak di Kelompok Bermain Al Azhar 1. Variabel pola asuh terdiri atas praktik pemberian makan dan perawatan kesehatan anak.

\section{METODE}

\section{Desain, tempat dan waktu}

Desain penelitian ini adalah cross sectional. Penelitian dilakukan di Kelompok Bermain Al Azhar 1, Kebayoran Baru, Jakarta Selatan pada bulan Maret hingga November 2019.

\section{Jumlah dan cara pengambilan subjek}

Subjek penelitian terdiri atas 25 balita usia 13-59 buland an dipilih secara purposive sampling.

\section{Jenis dan cara pengumpulan data}

Data penelitian diperoleh melalui wawancara kepada orangtua subjek penelitian. Data penelitian mencakup data karakteristik keluarga (usia, pendidikan, pekerjaan, pendapatan keluarga, dan pengeluaran pangan rumah tangga), status gizi, status kesehatan balita selama 2 minggu terakhir, dan praktik pemberian makan balita. Pengukuran berat badan menggunakan timbangan digital, sedangkan pengukuran tinggi badan menggunakan microtoise.

\section{Pengolahan dan Analisis data}

Data yang sudah dikumpulkan diolah dan dianalisis secara deskriptif menggunakan software Microsoft Excel 2013. Data praktik pemberian makan anak dikategorikan menjadi baik jika memiliki skor $\geq 83$ dan kurang jika skor $<83$. Data praktik perawatan kesehatan anak dikategorikan menjadi baik jika skor $\geq 85$ dan kurang jika skor $<85$. Penentuan cut off kategori variable praktik pemberian makan dan perawatan kesehatan balita ditentukan berdasarkan nilai rata-rata skor.

Status gizi balita dinilai berdasarkan tiga indikator gabungan yaitu berat badan menurut umur $(\mathrm{BB} / \mathrm{U})$, tinggi badan menurut umur $(\mathrm{TB} / \mathrm{U})$, dan berat badan menurut tinggi badan (BB/TB). Status gizi $(\mathrm{BB} / \mathrm{U})$ dikategorikan menjadi gizi kurang jika nilai z-score -3SD sd <-2SD, gizi baik jika nilai z-score 2SD sd 2 SD, gizi lebih jika nilai z-score $>2 S D$. Status gizi $(\mathrm{TB} / \mathrm{U})$ dikategorikan menjadi pendek jika nilai z-score -3SD sd <-2SD, normal jika nilai z-score -2SD sd $2 \mathrm{SD}$, tinggi jika nilai $\mathrm{z}$-score $>$ 2SD. Status gizi $(\mathrm{BB} / \mathrm{TB})$ dikategorikan menjadi kurus jika nilai z-score -3SD sd <-2SD, normal jika nilai z-score -2SD sd $2 \mathrm{SD}$, dan gemuk jika nilai zscore $>2$ SD. 


\section{HASIL DAN PEMBAHASAN}

\section{Karakteristik sosial ekonomi}

Subjek dalam penelitian ini merupakan siswa-siswi Kelompok Bermain Al Azhar 1 di Kebayoran Baru, Jakarta Selatan. Kelompok Bermain Al Azhar 1 terdiri atas kelas toddler Shafa, toddler Marwah, Kelompok Bermain Cordova, Kelompok Bermain Andalusia, TK A1, TK A2, TK A3, dan TK A4. Kriteria inklusi subjek dalam penelitian ini adalah balita usia 13 - 59 bulan dan orangtua/wali bersedia menjadi subjek penelitian dibuktikan dengan menandatangani surat persetujuan berpartisipasi penelitian (Informed Consent).

Tabel 1 menunjukkan sebaran subjek berdasarkan karakteristik sosial ekonomi. Berdasarkan Tabel 1 diketahui bahwa lebih dari separuh subjek berjenis kelamin laki-laki (68\%) dan hampir seluruh subjek berada pada usia dengan rentang 25 sampai 59 bulan (100\%). Sebagian besar usia ibu dan ayah subjek tergolong dewasa awal (26-35 tahun), yaitu berturut-turut sebesar $100 \%$ dan 96\%. Lebih dari separuh subjek memiliki jumlah anggota keluarga yang sedang yaitu antara empat hingga tujuh orang (72\%).Menurut [6] jumlah anggota keluarga yang besar semakin meningkatkan peluang untuk anak menjadi kekurangan gizi. Sebagian besar pendidikan ibu adalah sarjana (68\%) dan pendidikan ayah adalah pascasarjana (52\%). Hasil penelitian Adnan \& Muniandy (2012) menunjukkan bahwa tingkat pendidikan ibu berhubungan dengan praktik pemberian makan dan status gizi anak.Prevalensi tertinggi balita yang kurus terdapat pada balita dengan tingkat pendidikan ibu yang rendah [7].

Sebesar $40 \%$ ayah subjek bekerja sebagai pengusaha (wiraswasta) dan sebagian besar pekerjaan ibu adalah Ibu Rumah Tangga (40\%). Lebih dari separuh subjek memiliki pendapatan per bulan lebih dari Rp. 20 juta. Tingkat pendidikan ayah dan ibu subjek yang sebagian besar minimal sarjana menjadikan keluarga dapat dengan mudah mendapatkan akses pekerjaan yang layak dengan pendapatan yang tinggi. Hal ini sejalan dengan penelitian Nwokolo (2015) yang menyatakan bahwa tingkat pendidikan memegang peranan penting dalam meningkatkan pendapatan keluarga dan ketahanan pangan keluarga kt [8].
Tabel 1. Sebaran subjek berdasarkan karakteristik sosial ekonomi

\begin{tabular}{|c|c|c|}
\hline Keterangan & $\mathrm{n}$ & $\%$ \\
\hline \multicolumn{3}{|l|}{ Jenis Kelamin } \\
\hline Laki & 17 & 68 \\
\hline Perempuan & 8 & 32 \\
\hline \multicolumn{3}{|l|}{ Usia (bulan) } \\
\hline $13-36$ & 4 & 16 \\
\hline 24-59 & 21 & 84 \\
\hline \multicolumn{3}{|l|}{ Usia Ibu } \\
\hline Dewasa awal (26-35 Tahun) & 25 & 100 \\
\hline Dewasa akhir (36-45 Tahun) & 0 & 0 \\
\hline \multicolumn{3}{|l|}{ Usia Ayah } \\
\hline Dewasa awal (26-35 Tahun) & 24 & 96 \\
\hline Dewasa akhir (36-45 Tahun) & 1 & 4 \\
\hline \multicolumn{3}{|l|}{ Jumlah anggota keluarga (orang) } \\
\hline$<4$ orang & 4 & 16 \\
\hline 4-7 orang & 18 & 72 \\
\hline$>8$ orang & 3 & 12 \\
\hline \multicolumn{3}{|l|}{ Pendidikan Ayah } \\
\hline SMU & 2 & 8 \\
\hline Sarjana & 10 & 40 \\
\hline Pascasarjana & 13 & 52 \\
\hline \multicolumn{3}{|l|}{ Pendidikan Ibu } \\
\hline SMU & 0 & 0 \\
\hline Sarjana & 17 & 68 \\
\hline Pascasarjana & 8 & 32 \\
\hline \multicolumn{3}{|l|}{ Pekerjaan Ayah } \\
\hline PNS/TNI/Polisi & 6 & 24 \\
\hline Jasa (Misal: Dokter, Arsitek, dll) & 4 & 16 \\
\hline Karyawan Swasta & 5 & 20 \\
\hline Wiraswasta & 10 & 40 \\
\hline \multicolumn{3}{|l|}{ Pekerjaan Ibu } \\
\hline Ibu Rumah Tangga & 10 & 40 \\
\hline Jasa (Misal: Dokter, Arsitek, dll) & 4 & 16 \\
\hline Karyawan swasta & 5 & 20 \\
\hline PNS/TNI/Polisi & 2 & 8 \\
\hline Wiraswasta & 4 & 16 \\
\hline \multicolumn{3}{|l|}{ Pendapatan keluarga/bulan } \\
\hline Rp 10-15 juta & 7 & 28 \\
\hline Rp. 15 juta -20 juta & 5 & 20 \\
\hline$>$ Rp. 20 juta & 13 & 52 \\
\hline
\end{tabular}

\section{Status gizi}

Pertumbuhan merupakan salah satu indikator untuk menentukan status gizi, kesehatan, dan kesejahteraan anak. Status gizi balita dapat dinilai berdasarkan tiga indikator gabungan yaitu berat badan menurut umur $(\mathrm{BB} / \mathrm{U})$, tinggi badan menurut umur $(\mathrm{TB} / \mathrm{U})$, dan berat badan menurut tinggi badan $(\mathrm{BB} / \mathrm{TB})$. 
Indikator $\mathrm{BB} / \mathrm{U}$ adalah berat badan anak yang dicapai pada umur tertentu.Indikator $\mathrm{TB} / \mathrm{U}$ adalah tinggi badan yang dicapai pada umur tertentu. Indikator $\mathrm{BB} / \mathrm{TB}$ adalah berat badan anak dibandingkan dengan tinggi badan yang dicapai. Ketiga nilai indikator tersebut dibandingkan dengan standar baku dari badan kesehatan dunia maupun standar kementerian kesehatan. Asupan gizi yang cukup pada masa kanak-kanak dapat mendorong pencapaian kognitif dan mencegah timbulnya penyakit kronis di kemudian hari [9].

Tabel 2 menunjukkan bahwa sebagian besar subjek memiliki status gizi baik berdasarkan indeks berat badan menurut umur (BB/U) (88\%). Namun begitu, masih ditemukan balita dengan status gizi yang kurang (4\%) dan $8 \%$ memiliki status gizi yang lebih.Begitu juga dengan status gizi balita berdasarkan indeks tinggi badan menurut umur (TB/U) masih ditemukan sebesar $4 \%$ balita yang tergolong pendek.Sedangkan status gizi balita berdasarkan indeks berat badan menurut tinggi badan secara berturut-turut menunjukkan memiliki status gizi normal (84\%), gemuk (12\%), dan kurus $(4 \%)$.

Tingkat pendapatan sebagian besar orangtua subjek $(52 \%)$ yang berada pada kisaran lebih dari Rp. 20 juta/bulannya menjadikan anak memiliki akses mendapatkan pangan yang sehat dan bergizi, serta pelayanan kesehatan yang prima. Namun, penelitian [7] pada balita di Malaysia menunjukkan bahwa anak dari ibu dengan tingkat pendidikan diploma keatas memiliki prevalensi anak dengan status gizi berlebih yang lebih tinggi yaitu sebesar $13,9 \%$, konsumsi makanan cepat saji yang tinggi $(70,8 \%)$, dan lebih banyak yang melewatkan sarapan $(47,2 \%)$. Oleh karena itu, orangtua subjek yang memiliki tingkat pendidikan tinggi perlu diberikan pendidikan gizi akan pentingnya menjaga status gizi normal balitanya.

Tabel 2. Sebaran subjek berdasarkan status gizi (BB/U, $\mathrm{TB} / \mathrm{U}, \mathrm{BB} / \mathrm{TB}$ )

\begin{tabular}{lcc}
\hline Status Gizi & n & \% \\
\hline Status gizi (BB/U) & & \\
Gizi Kurang & 1 & 4 \\
Gizi Baik & 22 & 88 \\
Gizi Lebih & 2 & 8 \\
Status gizi (TB/U) & & \\
Sangat Pendek & 0 & 0 \\
Pendek & 1 & 4 \\
Normal & 23 & 92 \\
Tinggi & 1 & 4 \\
Status gizi (BB/TB) & & \\
\hline
\end{tabular}

\begin{tabular}{lcc}
\hline \multicolumn{1}{c}{ Status Gizi } & n & \% \\
\hline Kurus & 1 & 4 \\
Normal & 21 & 84 \\
Gemuk & 3 & 12 \\
\hline
\end{tabular}

\section{Praktik Pemberian Makan}

Kebiasaan makan yang baik dimulai dari rumah. Peran anggota keluarga dalam memengaruhi kebiasaan makan anak akan menentukan kebiasaan makan anak disaat dewasa. Oleh karena itu, anggota keluarga terutama ibu memegang peranan yang sangat penting dalam memberikan contoh tentang praktik pemberian makan anak yang baik Hal ini dikarenakan ibu biasanya memiliki waktu yang lebih banyak bersama anak, belanja bahan makanan, dan menyiapkan makanan untuk keluarga [10]. Hal ini sejalan dengan penelitian ini dimana sebagian besar subjek lebih banyak diasuh oleh ibu (64\%), dan sebesar 44\% subjek disiapkan makanannya oleh ibu.

Tabel 3 menunjukkan bahwa hampir sebagian besar subjek (84\%) kadang-kadang masih disuapi dan hanya sebesar $16 \%$ subjek yang selalu makan disuapi. Alasan ibu masih menyuapi makan anaknya adalah karena ibu khawatir makanan yang disiapkan justru tidak dimakan dan tempat makan anak menjadi kotor. Menurut [11] anak usia 3 sampai dengan 5 tahun sudah diajarkan untuk menaruh makanannya di piring makan anak. Selain itu, anak sudah harus diajarkan memegang sendok dan makan sendiri. Meskipun demikian, sebaiknya ibu tetap mengawasi makan anak walaupun tidak disuapi. Hasil penelitian ini juga menunjukkan bahwa sebagian besar ibu, kadang-kadang (56\%) masih tetap mengawasi makan anaknya walau tidak disuapi oleh ibu. Selain makan yang masih disuapi, hal yang tidak kalah penting adalah terkait jadwal makan anak. Jadwal makan anak yang teratur dapat menjamin kecukupan asupan zat gizi anak. Hasil penelitian menunjukkan bahwa lebih dari separuh subjek (60\%) ditentukan jadwal makannya oleh ibu. Masih terdapat $16 \%$ subjek yang jadwal makannya ditentukan oleh subjek sendiri. Sebagian besar subjek makan dengan jadwal yang teratur $(80 \%)$ dan porsi diberikan sesuai kebutuhan anak $(96 \%)$.

Sebanyak 40\% subjek memiliki situasi makan yang disiplin dan tidak boleh bermain dan sebanyak $40 \%$ subjek harus makan sambil bermain. Sebagian besar subjek $(52 \%)$ biasanya dikenalkan makanan baru dengan diberikan tersendiri, sementara sebesar $48 \%$ subjek harus diberikan bersama makanan yang sudah dikenal. Problema makan yang dihadapi 
subjek secara berturut-turut adalah diemut (40\%), pilih-pilih makanan (16\%), dan makan harus sambil main (16\%). Sebagian besar ibu subjek (72\%) tetap akan memberikan makanan dalam waktu yang berbeda jika anak menolak makanan tertentu. Hanya sebesar 20\% ibu subjek yang membuat inovasi makanan baru dengan bahan yang sama jika anak menolak makanan tertentu. Sebagian besar ibu subjek akan membujuk dan merayu subjek agar mau makan (60\%) dan hampir seluruh ibu subjek akan memuji subjek apabila menghabiskan makanannya (96\%). Sebesar 40\% subjek ditentukan jadwal minum susunya oleh ibu subjek dan sebesar 28\% ditentukan oleh subjek sendiri. Praktik pemberian makan pada anak baik dapat memengaruhi status gizi anak di saat dewasa. Pengetahuan dan sikap ibu diperlukan agar dapat memberikan makanan yang tepat untuk anak [12]. Selain itu, hasil penelitian menunjukkan bahwa kebiasaan makan orangtua dan strategi pemberian makan anak yang baik merupakan faktor paling dominan yang dapat memengaruhi perilaku makan anak dan pilihan makanan.Orangtua harus menjadi panutan positif dan memperkenalkan berbagai pilihan makanan yang baik kepada anak [13].

Tabel 4 menunjukkan distribusi kategori praktik pemberian makan anak yang terdiri atas kurang dan baik. Kategori kurang diperoleh jika skor dibawah 83 dan skor baik apabila memiliki skor lebih dari 83. Secara umum, sebagian besar orangtua subjek memiliki praktik pemberian makan yang baik (60\%). Hal ini diduga karena status sosial ekonomi keluarga subjek yang tergolong baik, sehingga akses terhadap pangan dan fasilitas kesehatan sangat terjamin.

Tabel 3. Sebaran subjek berdasarkan praktik pemberian makan anak

\begin{tabular}{|c|c|c|}
\hline Praktik Pemberian Makan & $\mathbf{n}$ & $\%$ \\
\hline \multicolumn{3}{|l|}{ Siapa yang sehari-hari lebih banyak mengasuh anak? } \\
\hline Ibu & 16 & 64 \\
\hline Nenek & 1 & 4 \\
\hline Pembantu & 8 & 32 \\
\hline \multicolumn{3}{|l|}{ Siapakah yang biasanya menyiapkan makanan anak? } \\
\hline Ibu & 11 & 44 \\
\hline Ibu dan orang lain & 8 & 32 \\
\hline Orang lain & 6 & 24 \\
\hline \multicolumn{3}{|l|}{ Apakah sampai sekarang anak masih disuapi ? } \\
\hline Kadang-kadang & 21 & 84 \\
\hline Selalu & 4 & 16 \\
\hline \multicolumn{3}{|l|}{ Apakah ibu mengawasi makan anak jika tidak menyuapi ? } \\
\hline Ya, selalu & 11 & 44 \\
\hline Kadang-kadang & 14 & 56 \\
\hline \multicolumn{3}{|l|}{ Siapakah yang menentukan jadwal makan anak? } \\
\hline Ibu sendiri & 15 & 60 \\
\hline Ibu dan orang lain & 6 & 24 \\
\hline Semau anak sendiri & 4 & 16 \\
\hline \multicolumn{3}{|l|}{ Apakah jadwal makan anak teratur? } \\
\hline Ya & 20 & 80 \\
\hline Tidak & 5 & 20 \\
\hline \multicolumn{3}{|l|}{ Bagaimanakah cara ibu menyajikan porsi makan anak? } \\
\hline Porsi makan dihidangkan sekaligus banyak & 1 & 4 \\
\hline Porsi makan sesuai kebutuhan anak & 24 & 96 \\
\hline \multicolumn{3}{|l|}{ Bagaimanakah situasi pada saat memberi makan anak? } \\
\hline Diusahakan disiplin dan tidak boleh bermain & 10 & 40 \\
\hline Sambil bermain di sekitar rumah & 10 & 40 \\
\hline Suasana tidak diperhatikan, asal makanan habis & 5 & 20 \\
\hline \multicolumn{3}{|c|}{ Bagaimanakah cara ibu memperkenalkan makanan baru kepada anak? } \\
\hline Diberikan tersendiri & 13 & 52 \\
\hline Diberikan bersama makanan yang sudah dikenal & 12 & 48 \\
\hline Apakah anak ibu mengalami problema sulit makan? & & \\
\hline
\end{tabular}




\begin{tabular}{lcc}
\hline \multicolumn{1}{c}{ Praktik Pemberian Makan } & n & \% \\
\hline Tidak ada problema makan & 7 & 28 \\
Pilih-pilih makanan (picky eater) & 4 & 16 \\
Diemut & 10 & 40 \\
Harus sambil main & 4 & 16 \\
Bagaimana sikap ibu jika anak menolak makanan tertentu ? & & 8 \\
Tidak diberikan lagi & 2 & 72 \\
Tetap diberikan dalam waktu yang berbeda & 18 & 20 \\
Membuat inovasi makanan baru dengan bahan yang sama & 5 & 4 \\
Bagaimana sikap ibu jika anak sulit makan? & 1 & 36 \\
Memaksa anak untuk makan & 60 \\
Membiarkan anak makan sesuai keinginannya & 9 & 4 \\
Membujuk atau merayu anak agar mau makan & 15 & 96 \\
Bagaimanakan sikap ibu jika anak menghabiskan makanannya? & & \\
Diam saja & 1 & 28 \\
Memujinya & 24 & 40 \\
Siapakah yang menentukan jadwal minum susu anak? & & 20 \\
Anak & 7 & 12 \\
Ibu & 10 & 5 \\
Ibu dan anak & 3 & \\
\hline
\end{tabular}

Tabel 4 Distribusi kategori praktik pemberian makan anak

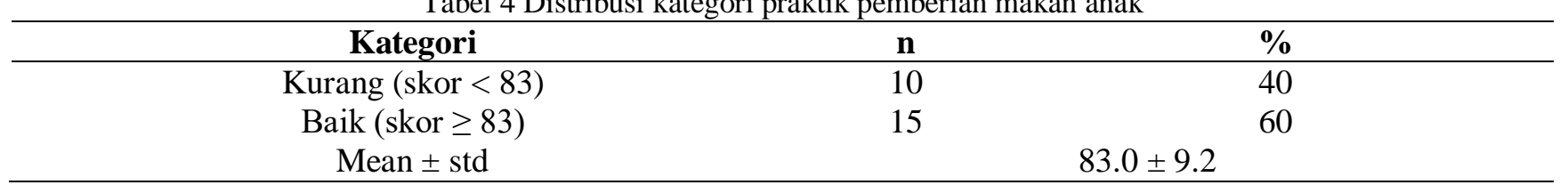

Tabel 5 Sebaran subjek berdasarkan perawatan kesehatan anak

\begin{tabular}{lcc}
\hline \multicolumn{1}{c}{ Perawatan kesehatan } & n & \% \\
\hline Ibu biasa memandikan anak balita menggunakan sabun mandi & & 0 \\
$\quad$ Kadang-kadang & 0 & 100 \\
Selalu & 100 & \\
Anak biasa cuci kaki sebelum tidur & 7 & 28 \\
$\quad$ Kadang-kadang & 18 & 72 \\
$\quad$ Selalu & & \\
Ibu mengajarkan anak untuk mulai membiasakan diri menggosok gigi sejak & 11 & 44 \\
$\quad \leq 1$ tahun & 14 & 56 \\
$1-2$ tahun & & \\
Ibu biasa mencuci rambut/keramas anak ......kali setiap minggu & 0 & 0 \\
$\quad \leq 3$ kali/minggu & 25 & 100 \\
$\geq 3$ kali/minggu & & \\
Anak menggosok gigi menggunakan pasta gigi....... & 1 & 4 \\
Kadang-kadang & 24 & 96 \\
Selalu & & \\
Ibu membiasakan anak menggunting kuku.....kali setiap bulan & 1 & 4 \\
1 kali/bulan & 13 & 52 \\
$2-3$ kali/bulan & 11 & 44 \\
$\geq 4$ kali/bulan (tiap minggu) & & \\
Anak mencuci tangan setelah buang air besar menggunakan......... & 2 & 8 \\
Air saja & &
\end{tabular}




\begin{tabular}{lcc}
\hline \multicolumn{1}{c}{ Perawatan kesehatan } & n & \% \\
\hline Air dan Sabun & 18 & 72 \\
Sabun dan air bersih (2x ulangan) & 5 & 20 \\
Anak biasa memakai alas kaki ketika bermain/berada di luar rumah & & \\
Kadang-kadang & 2 & 8 \\
Selalu & 23 & 92 \\
Anak biasa cuci tangan sebelum makan & & \\
Ya, cuci menggunakan sabun & 15 & 60 \\
Ya, kadang pakai sabun kadang tidak & 10 & 40 \\
\hline
\end{tabular}

\section{Perawatan kesehatan}

Tabel 5 menunjukkan bahwa seluruh subjek selalu mandi dengan menggunakan sabun. Lebih dari separuh subjek biasa cuci kaki sebelum tidur (72\%) dan sudah membiasakan sikat gigi sejak usia 1-2 tahun (56\%) menggunakan pasta gigi (96\%). Seluruh subjek keramas $\geq 3$ kali/minggu dan menggunting kuku 2-3 kali/bulan (52\%). Sebagian besar subjek mencuci tangan setelah buang air besar menggunakan air dan sabun $(72 \%)$, namun hanya terdapat $20 \%$ subjek yang mencuci tangan setelah buang air besar dengan air bersih dan sabun sebanyak dua kali ulangan. Masih terdapat $40 \%$ subjek yang belum mencuci tangan sebelum makan menggunakan sabun. Hasil penelitian Biran et al. 2014 menunjukkan bahwa mencuci tangan dengan sabun dapat secara signifikan mengurangi prevalensi diare dan infeksi saluran pernapasan, tetapi prevalensi cuci tangan yang baik dan benar masih rendah. Cuci tangan dengan air bersih dan sabun sebaiknya dilakukan dua kali ulangan di saat setelah buang air besar, sebelum persiapan makanan, dan sebelum makan [14].

Tabel 6 menunjukkan bahwa sebagian besar subjek $(84 \%)$ sudah tergolong memiliki perawatan kesehatan yang baik. Hal ini diduga karena tingkat pendidikan ibu dan ayah subjek yang minimal sarjana. Pendidikan yang tinggi dapat memengaruhi cara berpikir dan cara menggali informasi yang baik terhadap kesehatan anak. Orangtua subjek seringkali mendapatkan informasi kesehatan dari [15].

Tabel 6 Distribusi kategori perawatan kesehatan anak

\begin{tabular}{ccc}
\hline Kategori & n & \% \\
\hline Kurang $($ skor $<85)$ & 3 & 16 \\
Baik $($ skor $\geq 85)$ & 21 & 84 \\
Mean \pm std & \multicolumn{2}{c}{$85.0 \pm 4.9$} \\
\hline
\end{tabular}

\section{KESIMPULAN}

Sebagian besar subjek memiliki status gizi baik berdasarkan indeks berat badan menurut umur $(\mathrm{BB} / \mathrm{U})$, normal berdasarkan indeks tinggi badan menurut umur $(\mathrm{TB} / \mathrm{U})$, dan normal berdasarkan indeks tinggi badan menurut berat badan (BB/TB). Namun demikian, masih ditemukan subjek yang gizi kurang sebanyak satu orang, gizi lebih sebanyak dua orang, kurus sebanyak satu orang, dan gemuk sebanyak tiga orang. Secara umum, praktik pemberian makan anak dan perawatan kesehatan anak sebagian besar subjek tergolong baik.

\section{UCAPAN TERIMA KASIH}

Penulis menyampaikan terima kasih kepada Lembaga Penelitian dan Pengabdian Masyarakat (LP2M) Universitas Al Azhar Indonesia yang telah memberikan dana penelitian. Terima kasih juga disampaikan kepada Ibu Effie selaku Kepala kelompok Bermain Al Azhar 1.

\section{REFERENSI}

[1] Badan Perencanaan Pembangunan Nasional, Rencana Aksi Nasional Pangan dan Gizi 2011 - 2015. Jakarta: Bappenas, 2011.

[2] I. H. Jawad, K. H. Al-Jubori, and H. A. Baiee, "Prevalence and Associated Factors of Under Nutrition Among Under-Five Children in Babylon Province, Iraq,2016," Journal of University of Babylon for Pure and Applied Sciences, vol. 26, no. 3, 2018.

[3] I. Suparisa, B. Bakri, and and I. Fajar, Penilaian status gizi. Jakarta: Gizi Kedokteran EGC, 2002.

[4] A. E. Vaughn, D. S. Ward, and J. O. Fisher et all, "Fundamental constructs in food parenting 
practices: a content map to guide future research.," Nutr Rev, vol. 74, no. 2, pp. 98117, 2016.

[5] R. E. Black, C. G. Victora, S. P. Walker, and et all, "Maternal and child undernutrition and overweight in low-income and middle-income countries.," Lancet, vol. 382, no. 9890, pp. 427-451, 2013.

[6] K. O. Ajao, E. O. Ojofeitimi, A.A. Adebayo, and A. O. Fatusi et all, "Influence of family size, household food security status, and child care practices on the nutritional status of under-five children in Ile-Ife, Nigeria.," Afr $J$ Repord Health, vol. 14, no. 4, pp. 117-126, Desember 2010.

[7] N. Adnan and N. D. Muniandy, "The Relationship between Mothers' Educational Level and Feeding Practices among Children in Selected Kindergartens in Selangor, Malaysia: A Cross-sectional Study," Asian Journal of Clinical Nutrition, vol. 4, no. 2, pp. 39-52, 2012.

[8] E. E. Nwokolo, "The Influence of Educational Level on Sources of Income and Household Food Security in Alice, Eastern Cape, South Africa," Journal of Human Ecology, no. 3, pp. 208-217, 2017.

[9] K. Kim, S. C. Shin, and J. E. Shim, "Nutritional status of toddlers and preschoolers according to household income level: overweight tendency and micronutrient deficiencies.," Nutrition Research and Practice, vol. 9, no. 5, 2015.
[10] U. Yamborisut, P. Visetchart, W. Thasanasuwan, and et all, "Parental feeding practice is associated with child's body mass index in Thai school-aged children: A case study in Don Tum district, Nakhon Pathom, Thailand," Journal of Health Research, vol. 32, no. 1, pp. 82-94, 2018.

[11] J. B. Endres, R. E. Rockwell, and C. G. Mense, Food, Nutrition, and the young child. Ohio: Person Education Inc, 2004.

[12] N. Z. Rakhmawati and B.Panunggal, "Hubungan Pengetahuan dan Sikap Ibu dengan Perilaku Pemberian Makanan anak Usia 12-24 Bulan," Journal of Nutrition Collage, vol. 3, no. 1, 2014.

[13] S. Scaglioni et al., "Factors Influencing Children's Eating Behaviours.," Nutrients, vol. 10, no. 6, 2018.

[14] W. P. Schmidt, K. S. Varadharajan et all A. Biran, "Effect of a behaviour-change intervention on handwashing with soap in India (SuperAmma): a cluster-randomised trial.," Lancet Glob Health, vol. 2, no. 4, 2014.

[15] A. Iftikhar, A. Bari, I. Bano, and Q. Masood, "Impact of maternal education, employment and family size on nutritional status of children.," Pakistan Journal of Medical Sciences, vol. 33, no. 6, November 2017. 